\title{
Identification of a rare 17p13.3 duplication including the BHLHA9 and YWHAE genes in a family with developmental delay and behavioural problems
}

Valeria Capra ${ }^{1 \dagger}$, Marisol Mirabelli-Badenier ${ }^{2 \dagger}$, Michela Stagnaro ${ }^{2 \dagger}$, Andrea Rossi $^{3 \dagger}$, Elisa Tassano ${ }^{5 \dagger}$, Stefania Gimelli ${ }^{4 \dagger}$ and Giorgio Gimelli ${ }^{5^{*}}$

\begin{abstract}
Background: Deletions and duplications of the PAFAH1B1 and YWHAE genes in 17p13.3 are associated with different clinical phenotypes. In particular, deletion of PAFAH1B1 causes isolated lissencephaly while deletions involving both PAFAH1B1 and YWHAE cause Miller-Dieker syndrome. Isolated duplications of PAFAH1B1 have been associated with mild developmental delay and hypotonia, while isolated duplications of YWHAE have been associated with autism. In particular, different dysmorphic features associated with PAFAH1B1 or YWHAE duplication have suggested the need to classify the patient clinical features in two groups according to which gene is involved in the chromosomal duplication.

Methods: We analyze the proband and his family by classical cytogenetic and array-CGH analyses. The putative rearrangement was confirmed by fluorescence in situ hybridization.

Results: We have identified a family segregating a 17p13.3 duplication extending 329.5 kilobases by FISH and array-CGH involving the YWHAE gene, but not PAFAH1B1, affected by a mild dysmorphic phenotype with associated autism and mental retardation. We propose that BHLHA9, YWHAE, and CRK genes contribute to the phenotype of our patient. The small chromosomal duplication was inherited from his mother who was affected by a bipolar and borderline disorder and was alcohol addicted.
\end{abstract}

Conclusions: We report an additional familial case of small 17p13.3 chromosomal duplication including only BHLHA9, YWHAE, and CRK genes. Our observation and further cases with similar microduplications are expected to be diagnosed, and will help better characterise the clinical spectrum of phenotypes associated with 17p13.3 microduplications.

Keywords: Familial 17p13.3 duplication syndrome, PAFAH1B1 and YWHAE genes, Array-CGH

\section{Background}

The short arm of chromosome 17 is particularly prone to submicroscopic rearrangements due to the presence of high density low copy repeats (LCRs). The proximal region of the short arm harbors a number of syndromes such as CMT1A (Charcot-Marie-Tooth syndrome type 1A), HNPP (hereditary neuropathy with liability to

\footnotetext{
* Correspondence: giorgio.gimelli@gmail.com

${ }^{\dagger}$ Equal contributors

${ }^{5}$ Laboratorio di Citogenetica, Istituto G. Gaslini, Genova, Italy

Full list of author information is available at the end of the article
}

pressure palsies), Smith-Magenis syndrome, and PotockiLupski syndrome. It is known that heterozygous 17p13.3 deletions, including PAFAH1B1 (MIM 601545) and YWHAE (MIM 605066) genes, cause two clinically distinct disorders: LSI (isolated lissencephaly) or MDS (Miller-Dieker syndrome), depending on the size of the deletion [1]. Recently, new genomic disorders have been identified in the MDS locus. To date, twenty-two microdeletions [2-6] and sixteen microduplications [5,7-9] overlapping the MDS critical region have been described in unrelated individuals. All these submicroscopic rearrangements are 
variable in size and have distinct breakpoints. Bruno et al. [5] proposed to divide 17p13.3 microduplications in two different classes: class I microduplications involving YWHAE but not PAFAH1B1 showing a phenotype characterized by learning difficulties and/or autism with or without other congenital abnormalities; class II microduplications always harboring PAFAH1B1 that may also include the genomic region encompassing the $C R K$ and $Y W H A E$ genes, which are associated with developmental delay, psychomotor delay, and associated hypotonia.

Here we report on a 7-year-old boy and his mother presenting a novel class I 17p13.3 microduplication measuring about $329.5 \mathrm{~Kb}$ in length and involving only seven genes, including YWHAE, CRK, and BHLHA9.

\section{Methods}

\section{Case presentation}

The proband, a 7-year-old boy with a Caucasian ancestry, is the third child of non-consanguineous parents. The mother presents antisocial behaviour and bipolar disorder, she was HIV positive and alcohol addicted. The father was drug addicted, but was not available for array-CGH analysis. One sister was reported as healthy while a second one was reported to manifest behavioural problems and aggressiveness. Both sisters were not available for testing because they were living apart from their brother. The proband is currently legally in care of his maternal grandparents, but lives with his maternal uncle. His maternal grandmother was affected by depression and has been recently diagnosed as having bilateral breast cancer. His maternal grandmother and maternal uncle were available for array-CGH analysis (Figure 1A).

The child was born at 37 weeks of gestation by caesarean section after a pregnancy complicated by gestosis. His birthweight was 3350 g, length and head circumference were not reported. APGAR score was 8 and 9 at first and fifth minute. At eight months of age, because of motor delay and mild lower limb hypertonia, transfontanellar ultrasound was performed and it appeared normal. The patient underwent physiotherapy treatment for one year with partial improvement. He was able to walk at 18 months of age and uttered his first words at 2 years of age. Moreover, poor social relationships and motor stereotypes were noticed. He presented appropriate growth. At five years five months of age, his neurological examination was characterized by clumsiness without obvious focal signs. A moderate mental retardation was noticed: the General Developmental Quotient assessed according to the Griffiths Mental Development Scale was 46. Behavioural and neuropsychological evaluations revealed an autism defined as a pervasive developmental disorder not otherwise specified (PDD-NOS) with social interaction and communication impairment, motor stereotypes, persistent behaviours, and attention deficit. At seven years five months of age, weight was $22.8 \mathrm{~kg}\left(50^{\text {th }}\right.$ centile), height $123 \mathrm{~cm}\left(75^{\text {th }}\right.$ centile $)$, and head circumference $52.5 \mathrm{~cm}\left(25^{\text {th }}-50^{\text {th }}\right.$ centile $)$. At physical examination, the child presented thick linearized eyebrows, myopia with upslanting eyes, squared upturned tip of the nose, pointed chin, large and low-set ears. His hands were short and stubby with low-set thumbs (Figure 1B). Both feet presented laterally set fifth toes. Laboratory investigations for metabolic disorders (ammonium, lactic acid, creatine kinase, aminoacids in serum and urine, organic acids and creatine/ guanidinoacetate in urine, isoelectric focusing of serum transferrin) were normal. Ophthalmologic evaluation, electroencephalogram and auditory evoked potentials were also normal. Brain MRI performed at five years five months of age revealed reduction of the volume and thickness of the isthmus and of the splenium of the corpus callosum with a dysmorphic aspect of the rostrum. No lesions of the supratentorial tissues were identified. Both cerebellar hemispheric and vermian folia, in the subtentorial regions, were wilted without signal alteration (Figure 2). A control MRI after one year confirmed the presence of non-progressive neuroradiologic features characterized by posterior corpus callosum hypoplasia and mild cerebellar hypoplasia. Molecular analysis for Fragile-X syndrome was negative. The mother was not available for clinical evaluation or MRI screening but consented to cytogenetic analysis.

\section{Cytogenetic, Fluorescence in situ hybridization and array-CGH analyses}

Cytogenetic analysis was performed using GTG-banding techniques on metaphase chromosomes obtained by standard procedures from peripheral blood lymphocytes. FISH analyses, according to standard protocols, were carried out using BlueFISH BAC probes (http://www. cambridgebluegnome.com/bluefish) RP11-294J5 and RP11100F18 mapping to $17 \mathrm{p} 13.3$ at the positions chr17:1, 199,461-1,352,559 and chr17:1,314,902-1,514,082 (build 37.1, Feb 2009), respectively. Array-CGH was additionally performed on the proband and other family members using the Agilent Human Genome CGH Microarray Kit G3 400K (Agilent Technologies, Santa Clara, CA, USA) platform, according to the manufacturer's instructions. This high resolution 60-mer oligonucleotide-based microarray spans coding and non coding genomic sequences with a median spacing of $5.3 \mathrm{~kb}$. Data analysis was performed using the Agilent Genomic Workbench Lite Edition Software 6.5.0.18(2) with the following settings for $\mathrm{CGH}$ aberration calling: ADM-2 algorithm (threshold 5) with a moving average of $500 \mathrm{~KB}$ and visual inspection of the log2 ratios. DNA sequence information was according to the UCSC Genome Browser (http:// genome.ucsc.edu/; GRCh37/hg19, February 2009). 

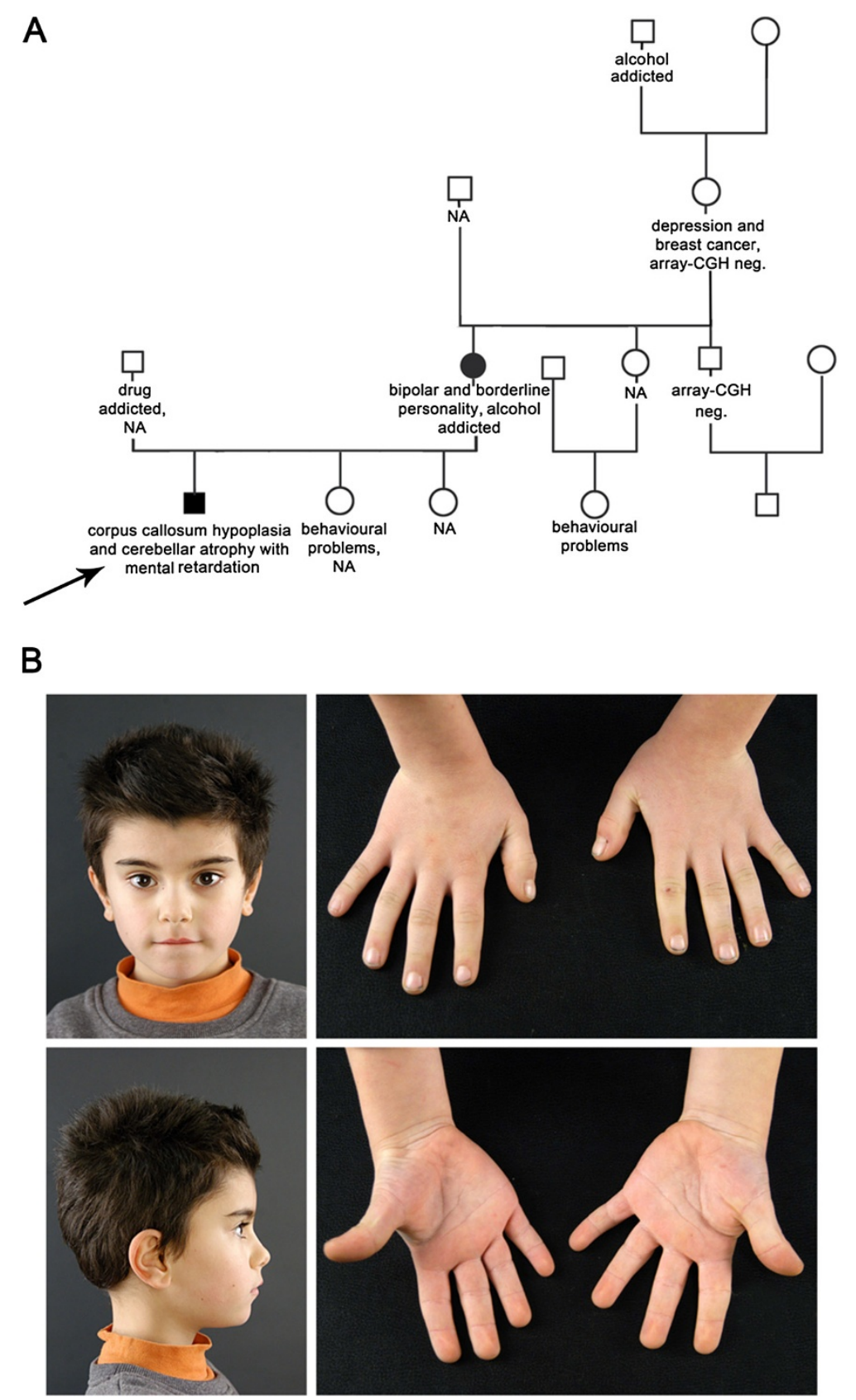

Figure $1 \mathrm{~A}$ ) Family tree that shows the individuals who were available for array-CGH. Some components of the family were reported as being affected by behavioural deficits. Arrow indicates the affected child. Full symbols indicate the individuals carrying the 17p13.3 duplication. NA indicates the individuals not available for array-CGH. B) Photographs of face and hands of the child carrying the 17p13.3 duplication. Mild facial anomalies such as thickened eyebrows, upslanting eyes, squared nasal tip, large and low-set ears. Short and stubby hands with low-set thumbs. The step mother gave consent to publish the photoghaphs of the child.

\section{Results}

The patient and his mother had a normal G-band karyotype. The array CGH analysis revealed a 17p13.3 duplication of $\sim 329.5 \mathrm{~Kb}$ between oligomers at $1,122,235 \mathrm{Mb}$ (A_18_P12560163, first duplicated) and $1,451,751 \mathrm{Mb}$ (A_16_P20564512, last duplicated), flanked by oligomers at $1,117,136 \mathrm{Mb}$ (A_16_P20563792, first present) and
$1,455,928 \mathrm{Mb}$ (A_16_P03201459, last present), in the patient and his mother, while his maternal grandmother and his maternal uncle had normal array-CGH analysis (Figure 3A). FISH studies with BACs RP11-294J5 and RP11-100F18 excluded a more complex rearrangement and the insertion of the duplicated segment in another chromosome. The duplicated region contains only seven 


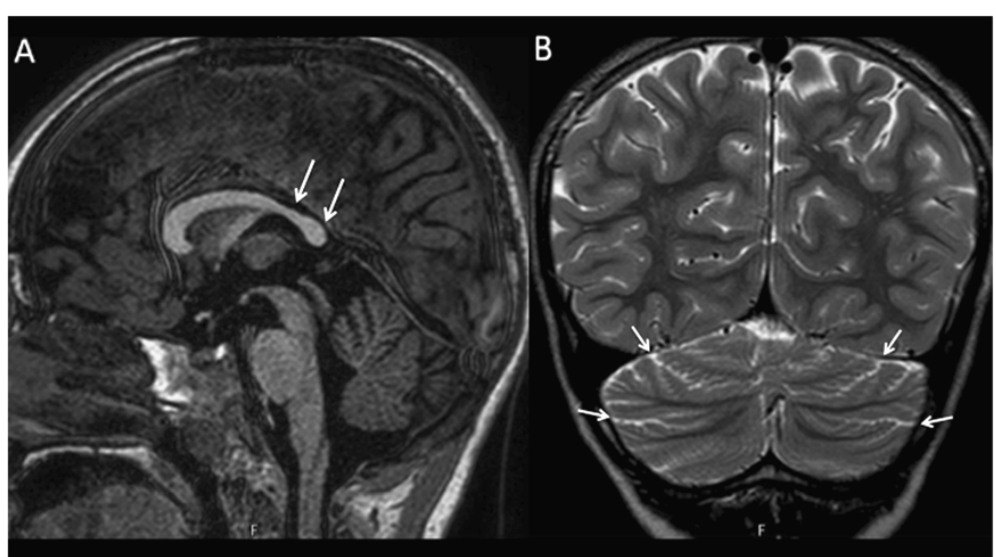

Figure 2 MR imaging. A) sagittal turbo-field-echo T1-weighted image shows hypoplastic callosal splenium (arrows). B) coronal fast spin-echo T2-weighted image shows slightly prominent cerebellar fissures (arrows), consistent with a mild form of cerebellar hypoplasia.

genes: BHLHA9 (basic helix-loop-helix family, member a9), TUSC5 (tumor suppressor candidate 5), YWHAE (tyrosine 3-monooxygenase/tryptophan 5-monooxygenase activation protein, epsilon polipeptide), $C R K$ (v-crk avian sarcoma virus CT10 oncogene homolog), MYO1C (MYOSIN 2), INPP5K (inositol polyphosphate 5-phosphatase K), PITPNA (phosphatidylinositol transfer protein alpha isoform) (intron 9) (Figure 3B).

\section{Discussion}

The use of array-CGH analyses for investigation of children with mental retardation has led to the identification of a growing number of new microdeletion and microduplication syndromes, some of which have been clinically well characterised while some other await further delineation.

A)
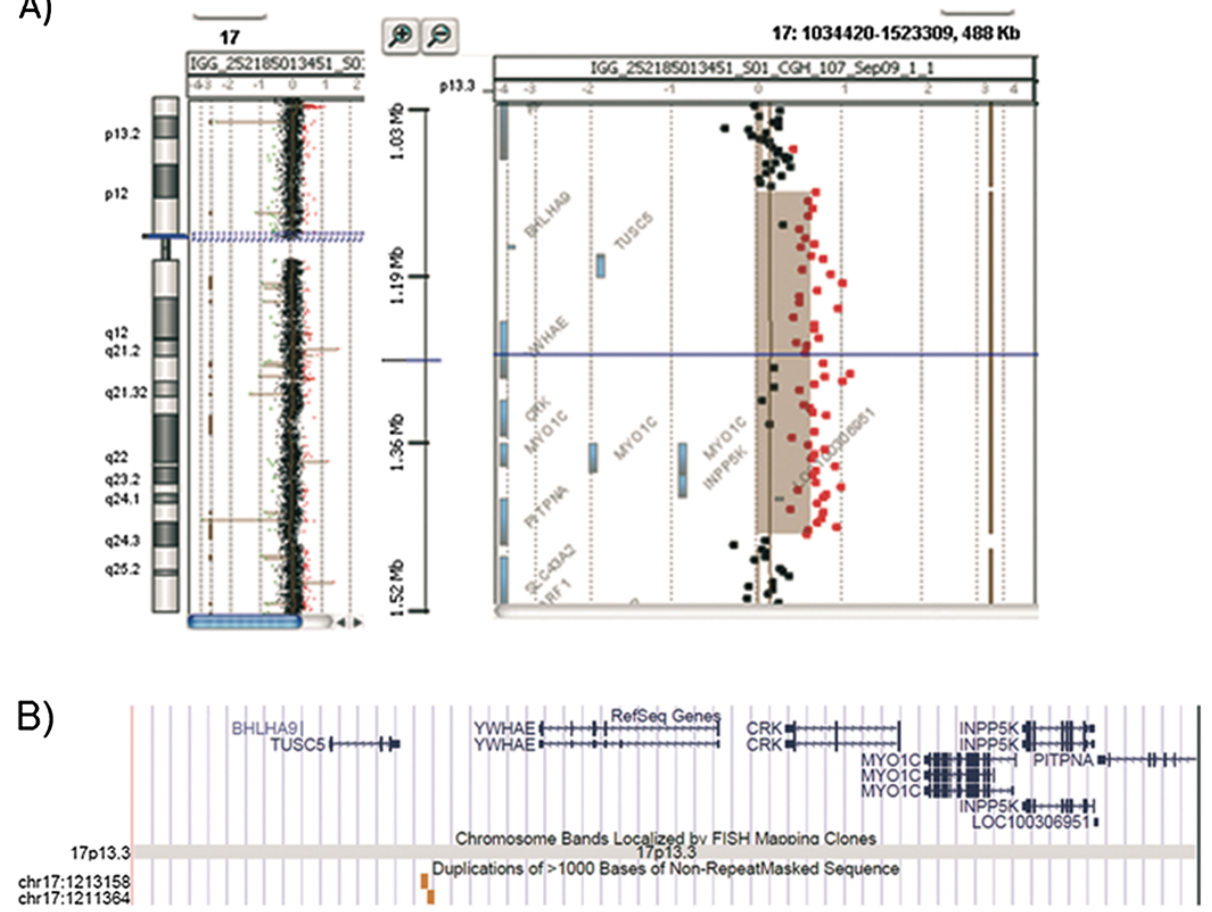

Figure 3 A) Result of array-CGH analysis of chromosome 17 with Agilent Human Genome CGH microarray Kit G3 400K. The 17p13.3 duplicated region extends between probes A_18_P12560163 (1,122,235Mb) and A_16_P20564512 (1,451,751Mb). B) Gene contents of the duplicated region. 
The proximal short arm of chromosome 17 is particularly prone to cryptic rearrangements for the presence of a high density of low copy repeats. The Miller-Dieker syndrome (MDS) is localized in the more distal region 17p13.3 containing the PAFAH1B1 (encoding LIS1) and $Y W H A E$ genes. Recently, novel co-locating microdeletions and microduplications in chromosome $17 \mathrm{p} 13.3$ were identified by array-CGH describing new genomic disorders in the MDS locus. Most of these rearrangements are non-recurring and vary in size, from one hundred kilobases to about three megabases. The clinical characterization of both microdeletions and microduplications has been dissected according to the extension and the genes involved in such rearrangements. The main characteristics of $17 \mathrm{p} 13.3$ microdeletion are significant postnatal growth retardation, mild to moderate mental retardation, and facial anomalies.

Our patient and his mother have an interstitial microduplication of about $329.5 \mathrm{Kbs}$ containing only seven genes. Many other patients with microduplications of varying size have been reported with different breakpoints and gene content $[5,7,9]$. Bruno et al.[5] reported on two cases (cases 9 and 11) in which duplicated regions overlapped the one reported here, containing $C R K, Y W H A E$, and BHLA9 genes. Only the duplication described by $\mathrm{Bi}$ et al., [9] (subject 2) is superimposable on that described here, while the duplicated region of subject 1 spans $240 \mathrm{~Kb}$ and contains only four genes: TUSC5, YWHAE, CRK, and MYO1C (Figure 4). Among the genes comprised in the duplicated region, particular interest has been paid to YWHAE. YWHAE is a gene encoding 14-3-3epsilon, which is highly conserved across species, from bacteria to humans, and binds to phosphoserine/phosphothreonine motifs in a sequence-specific manner. The individuals with duplications including YWHAE are characterized by a milder neurocognitive and pervasive developmental disorder phenotype, and share some minor craniofacial abnormalities [9]. The main phenotypic features of the patients include autistic manifestations, behavioral symptoms, developmental delay, varying degree of mental retardation, speech delay, several common facial features, and subtle hand/foot malformations. Three families were reported [10] with split-hand/foot malformation and long bone deficiency (SHFLD); the same authors suggested that a locus responsible for this condition is located within a duplicated segment on $17 \mathrm{p} 13.3$ band containing $A B R$ and BHLHA9 genes. In another study, seventeen patients with $17 \mathrm{p} 13.3$ duplication, among 56 families with SHFLD syndrome, showed a minimal critical region encompassing the BHLHA9 gene [11]. Therefore, the authors concluded that the $17 \mathrm{p}$ duplication could be
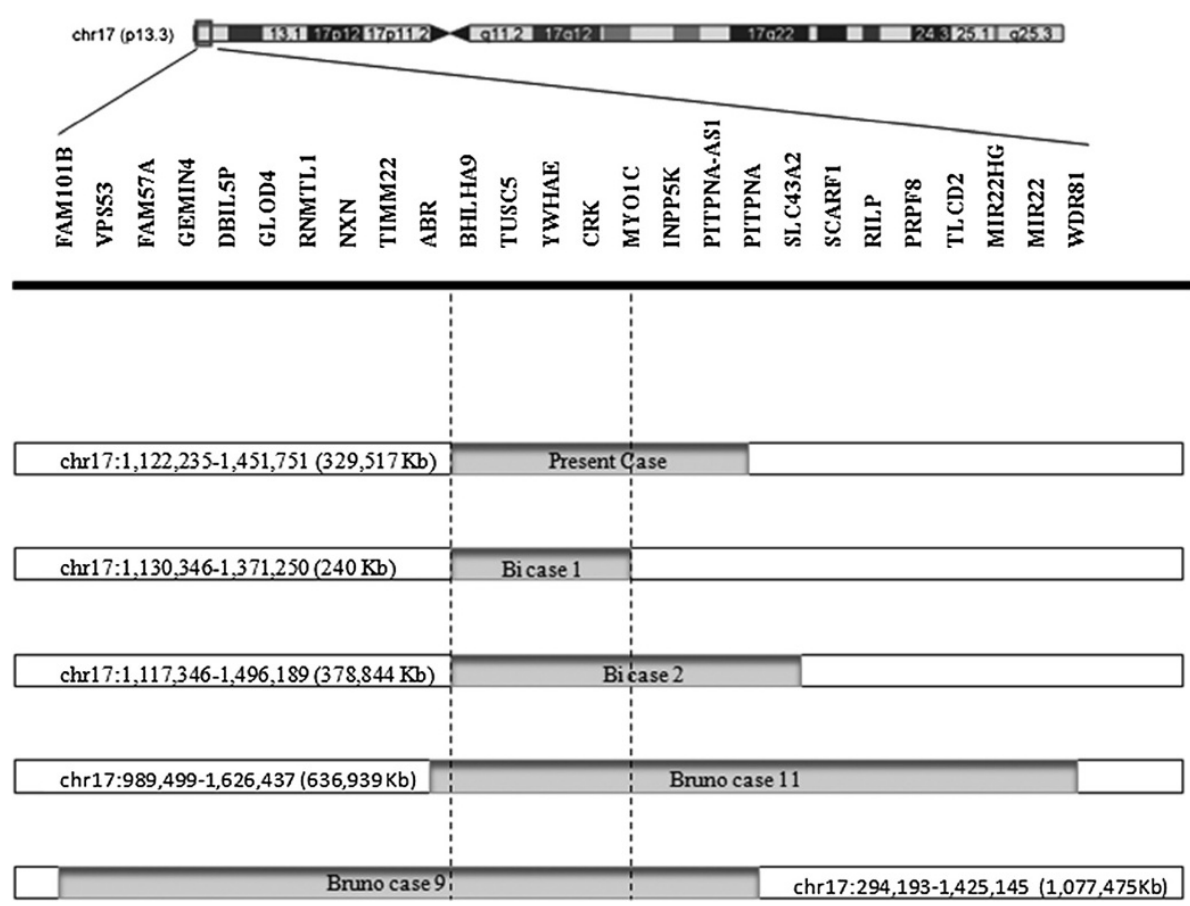

Figure 4 Schematic representation of five 17p13.3 duplications in relation to gene content. Enlargement of band p13.3 of chromosome 17. For each individual, the solid lines (grey shading) below the map represent duplicated regions and nucleotide positions are indicated according to UCSC Genome Browser Build 36.12009 (nucleotide positions of Bi cases 1 and 2 and Bruno cases 9 and 11 were converted from $\mathrm{Hg} 18$; nucleotide position of Bi case 1 was deduced (not indicated in the report). The dotted lines restrict the minimal critical region of overlap for 17p13.3 microduplications in the five cases. 
considered as a susceptibility locus for SHFLD, which is necessary but not sufficient for the development of these malformations. The high degree of non-penetrance could be dependent on other modifiers not identified yet.

Bruno et al. [5] suggested that there are two classes of co-locating microduplications on $17 \mathrm{p} 13.3$. Class I duplications involve YWHAE, but not PAFAH1B1 and the patients show autistic manifestation and behavioral problems, speech and motor delay, mild dysmorphic facial features, subtle hand and foot anomalies, and tendency to overgrowth. Class II microduplications always involve PAFAH1B1 and may extend to CRK and YWHAE and have been associated to hypotonia, mild developmental, and psychomotor delay. Some dysmorphic features as prominent forehead and pointed chin, sometimes associated with microcephaly and growth restriction, are the most common characteristics [5]. Our patient is tall with mild facial anomalies like upslanting eyes, squared nasal tip, normal chin, large and low-set ears, short hands with low-set thumbs, while the feet had laterally set fifth toes. Moderate mental retardation was associated with a pervasive developmental disorder not otherwise specified (PDD-NOS) with social interactions and communication impairment, motor stereotypes, perseveration behaviours, and attention deficit. Brain MRI identified the presence of non-progressive neuroradiological features characterized

Table 1 Phenotypic features of patient with 17p13.3. class I microduplication

\begin{tabular}{|c|c|c|c|c|c|}
\hline & Index case & Bi et al., subject 1 & Bi et al., subject 2 & Bruno et al., case 9 & Bruno et al., case 11 \\
\hline Age & 8 years & 6 years & 8 years & 2 years & 14 years \\
\hline Gender & $M$ & M & $\mathrm{F}$ & M & $M$ \\
\hline Gestational age (weeks) & 37 & NA & At term & At term & At term \\
\hline Birth weight (g) & 3350 & 3900 & 4592 & 3400 & 3487 \\
\hline Birth length $(\mathrm{cm})$ & NA & NA & 57 & 51 & $\mathrm{~N}$ \\
\hline Birth head circumference $(\mathrm{cm})$ & NA & NA & NA & NA & $50^{\text {th }}$ centile \\
\hline Postnatal growth retardation & - & - & - & - & - \\
\hline Overgrowth & $+\left(75^{\text {th }}\right.$ centile $)$ & $+\left(90^{\text {th }}\right.$ centile $)$ & $+3 \mathrm{SD}$ & - & $+\left(90-97^{\text {th }}\right.$ centile $)$ \\
\hline Feeding difficulties & - & - & - & - & + \\
\hline Muscle hypotonia & + & + & + & - & + \\
\hline Delay in motor function & + & + & + & $\begin{array}{l}\text { Delay in fine } \\
\text { motor skills }\end{array}$ & + \\
\hline Cognitive development & Global delay & $\begin{array}{l}\text { Mild to moderate } \\
\text { global delay }\end{array}$ & Global delay & Normal at 2 years & Mild delay \\
\hline Speech delay & ++ & ++ & ++ & + & + \\
\hline Neurobehavioural symptoms & PDD-NOS & $\begin{array}{l}\text { Behavior problems, } \\
\text { aggressive tendencies }\end{array}$ & $\begin{array}{l}\text { Behavior problems } \\
\text { particularly with food }\end{array}$ & Autism, hyperactivity & Autism trait, facial tic \\
\hline Repeated infection & - & NA & NA & - & - \\
\hline \multicolumn{6}{|l|}{ Facial features: } \\
\hline Face & Triangular & & & Triangular & $\mathrm{N}$ \\
\hline Forehead & Broad & & Broad & Broad & $\mathrm{N}$ \\
\hline Eyes & $\begin{array}{l}\text { Thick eyebrows, } \\
\text { upslanting palpebral } \\
\text { fissures }\end{array}$ & $\begin{array}{l}\text { Thick eyebrows, } \\
\text { synophrys }\end{array}$ & $\begin{array}{l}\text { Upslanting palpebral } \\
\text { fissures, synophrys }\end{array}$ & $\mathrm{N}$ & Broad, sparse eyebrows \\
\hline Nose & $\begin{array}{l}\text { Squared upturned } \\
\text { tip of the nose }\end{array}$ & $\begin{array}{l}\text { Squared, overhanging } \\
\text { columella }\end{array}$ & Squared & $\mathrm{N}$ & Squared, upturned tip \\
\hline Ears & Large & Large & Large & Prominent & Large, fleshy \\
\hline Mouth & Thin & Thin upper lip & Thin upper lip & $\begin{array}{l}\text { Prominent cupid } \\
\text { bow }\end{array}$ & Prominent cupid bow \\
\hline Mandible & Pointed chin & NA & Prominent chin & Pointed chin & Pointed chin \\
\hline Hands/feet anomalies & $\begin{array}{l}\text { Short and stubby } \\
\text { with low-set thumbs }\end{array}$ & $\begin{array}{l}\text { Large hands, small } \\
\text { distal phalanges }\end{array}$ & Large hands & $\begin{array}{l}\text { Bilateral groove } \\
\text { between toe } \\
\text { one and two }\end{array}$ & $\begin{array}{l}\text { Hallux valgus, } \\
\text { sandal gap, abnormal } \\
\text { toe nails }\end{array}$ \\
\hline Associated malformations & - & - & - & - & Genu valgum \\
\hline $\mathrm{MRI}$ & $\begin{array}{l}\text { Corpus callosum } \\
\text { hypoplasia and mild } \\
\text { cerebellar hypoplasia }\end{array}$ & NA & Thin corpus callosum & NP & NP \\
\hline
\end{tabular}


by posterior corpus callosum hypoplasia and mild cerebellar hypoplasia. According to the identified duplication involving YWHAE, but not PAFAH1B1, our patient could fit as having a class I duplication. Furthermore, his clinical phenotype seems to overlap the features previously identified in such patients, as showed in Table 1.

However, in the patient's family history we have to consider that his mother presented antisocial behaviour, bipolar disorder, and alcoholism, but unfortunately she was not available for clinical evaluation or MRI tests. Furthermore, his father was drug addicted and his grandmother was affected by depression. Several environmental problems, intertwining with genetic factors, affect this family. Although genetic and environmental influences may work independently, research is beginning to acknowledge that these factors work in concert to influence the behavioral phenotype, as depression and anxiety [12]. We should therefore consider the $17 \mathrm{p} 13.3$ duplication in terms of genetic contribution to a phenotype that, especially in his mother, seems to be due to different components.

\section{Conclusions}

In conclusion, our report contributes to a better definition of the minimal critical region for class 1 microduplications including BHLHA9, YWHAE, and CRK. Additional patients will be necessary to further substantiate the significance of $17 \mathrm{p} 13.3$ microduplications and to establish a better genotype-phenotype correlation.

\section{Consent}

Written informed consent was obtained from the patient for publication of this case report and any accompanying images. A copy of the written consent is available for review by the Editor-in-Chief of this journal.

\section{Competing interests}

The authors declare that they have no competing interests related to this manuscript.

\section{Authors' contributions}

All authors reviewed the manuscript critically for its content, revised and edited it, and approved the final version.

\footnotetext{
Author details

'U.O. Neurochirurgia, Istituto G.Gaslini, Genova, Italy. ${ }^{2}$ U.O. Neuropsichiatria, Istituto G.Gaslini, Genova, Italy. ${ }^{3}$ Dipartimento di Neuroradiologia, Istituto G. Gaslini, Genova, Italy. ${ }^{4}$ Service of Genetic Medicine, University Hospitals of Geneva, Geneva, Switzerland. '5aboratorio di Citogenetica, Istituto G. Gaslini, Genova, Italy.
}

Received: 21 March 2012 Accepted: 1 October 2012

Published: 4 October 2012

\section{References}

1. Toyo-oka K, Shionoya A, Gambello MJ, Cardoso C, Leventer R, Ward HL, Ayala R, Tsai LH, Dobyns W, Ledbetter D, Hirotsune S, Wynshaw-Boris A: 4-3-3epsilon is important for neuronal migration by binding to NUDEL: a molecular explanation for Miller-Dieker syndrome. Nat Genet 2003, $34: 274 \mathrm{e} 85$.
2. Østergaard JR, Graakjær J, Brandt C, Birkebæk NH: Further delineation of 17p13.3 microdeletion involving CRK. The effect of growth hormone treatment. Eur J Med Genet 2012, 55(1):22-26.

3. Mignon-Ravix C, Cacciagli P, El-Waly B, Moncla A, Milh M, Girard N, Chabrol B, Philip N, Villard L: Deletion of YWHAE in a patient with periventricular heterotopias and marked corpus callosum hypoplasia. J Med Genet 2010, 47:132-136.

4. Sreenath Nagamani SC, Zhang F, Shchelochkov OA, Bi W, Ou Z, Scaglia F, Probst FJ, Shinawi M, Eng C, Hunter JV, Sparagana S, Lagoe E, Fong CT, Pearson M, Doco-Fenzy M, Landais E, Mozelle M, Chinault AC, Patel A, Bacino CA, Sahoo T, Kang SH, Cheung SW, Lupski JR, Stankiewicz P: Microdeletions including YWHAE in the Miller-Dieker syndrome region on chromosome 17p13.3 result in facial dysmorphisms, growth restriction, and cognitive impairment. J Med Genet 2009, 46:825-833.

5. Bruno DL, Anderlid BM, Lindstrand A, van Ravenswaaij-Arts $C$, Ganesamoorthy D, Lundin J, Martin CL, Douglas J, Nowak C, Adam MP, Kooy RF, Van der Aa N, Reyniers E, Vandeweyer G, Stolte-Dijkstra I, Dijkhuizen T, Yeung A, Delatycki M, Borgström B, Thelin L, Cardoso C, van Bon B, Pfundt R, de Vries BB, Wallin A, Amor DJ, James PA, Slater HR, Schoumans J: Further molecular and clinical delineation of co-locating 17 p13.3 microdeletions and microduplications that show distinctive phenotypes. J Med Genet 2010, 47:299-311.

6. Schiff M, Delahaye A, Andrieux J, Sanlaville D, Vincent-Delorme C, Aboura A, Benzacken B, Bouquillon S, Elmaleh-Berges M, Labalme A, Passemard S, Perrin L, Manouvrier-Hanu S, Edery P, Verloes A, Drunat S: Further delineation of the 17p13.3 microdeletion involving YWHAE but distal to PAFAH1B1: four additional patients. Eur J Med Genet 2010, 53(5):303-308.

7. Hyon C, Marlin S, Chantot-Bastaraud S, Mabboux P, Beaujard MP, Al Ageeli E, Vazquez MP, Picard A, Siffroi JP, Portnoï MF: A new 17p13.3 microduplication including the PAFAH1B1 and YWHAE genes resulting from an unbalanced X;17 translocation. Eur J Med Genet 2011, 54:287-291.

8. Roos L, Jonch AE, Kjaergaard S, Taudorf K, Simonsen H, Hamborg-Petersen $B$, Brondum-Nielsen $K$, Kirchhoff M: A new microduplication syndrome encompassing the region of the Miller-Dieker (17p13 deletion) syndrome. J Med Genet 2009, 46:703e10.

9. Bi W, Sapir T, Shchelochkov OA, Zhang F, Withers MA, Hunter JV, Levy T, Shinder V, Peiffer DA, Gunderson KL, Nezarati MM, Shotts VA, Amato SS, Savage SK, Harris DJ, Day-Salvatore DL, Horner M, Lu XY, Sahoo T, Yanagawa Y, Beaudet AL, Cheung SW, Martinez S, Lupski JR, Reiner O: Increased LIS1 expression affects human and mouse brain development. Nat Genet 2009, 41:168e77.

10. Armour CM, Bulman DE, Jarinova $O$, Rogers RC, Clarkson KB, DuPont BR, Dwivedi A, Bartel FO, McDonell L, Schwartz CE, Boycott KM, Everman DB, Graham GE: 17p13.3 microduplications are associated with split-hand/ foot malformation and long-bone deficiency (SHFLD). Eur J Hum Genet 2011, 19:1144-1151.

11. Klopocki E, Lohan S, Doelken SC, Stricker S, Ockeloen CW, Soares Thiele de Aguiar R, Lezirovitz K, Mingroni Netto RC, Jamsheer A, Shah H, Kurth I, Habenicht R, Warman M, Devriendt K, Kordaß U, Hempel M, Rajab A, Mäkitie O, Naveed M, Radhakrishna U, Antonarakis SE, Horn D, Mundlos S: Duplications of BHLHA9 are associated with ectrodactyly and tibia hemimelia inherited in non-Mendelian fashion. J Med Genet 2012, 49:119-125.

12. Caspi A, Moffitt TE: Gene-environment interactions in psychiatry: joining forces with neuroscience. Nat Rev Neurosci 2006, 7:583-590.

\section{doi:10.1186/1471-2350-13-93}

Cite this article as: Capra et al.: Identification of a rare $17 \mathrm{p} 13.3$ duplication including the BHLHA9 and YWHAE genes in a family with developmental delay and behavioural problems. BMC Medical Genetics 2012 13:93 